\title{
Tangence
}

Jean Morency, Le mythe américain dans les fictions

d'Amérique de Washington Irving à Jacques Poulin, Québec, Nuit blanche éditeur, 1994, 258 p.

\section{Yvan Lamonde}

Numéro 48, octobre 1995

Montréal et Vancouver : parcours urbains dans la littérature et le cinéma

URI : https://id.erudit.org/iderudit/025871ar

DOI : https://doi.org/10.7202/025871ar

Aller au sommaire du numéro

Éditeur(s)

Tangence

ISSN

0226-9554 (imprimé)

1710-0305 (numérique)

Découvrir la revue

Citer ce compte rendu

Lamonde, Y. (1995). Compte rendu de [Jean Morency, Le mythe américain dans les fictions d'Amérique de Washington Irving à Jacques Poulin, Québec, Nuit blanche éditeur, 1994, 258 p.] Tangence, (48), 161-163.

https://doi.org/10.7202/025871ar d'utilisation que vous pouvez consulter en ligne.

https://apropos.erudit.org/fr/usagers/politique-dutilisation/ 


\section{|'R!}

\section{Jean Morency, Le mythe américain dans les fictions d'Amérique, de Washington Irving à Jacques Poulin, Québec, Nuit blanche éditeur, 1994, 258 p.}

Cette étude claque comme un coup de tonnerre dans le ciel des idées et de la littérature québécoises. L'analyse fera étape parce qu'elle donne un souffle nouveau et radical à l'étude de la littérature et de l'américanité québécoises.

L'américanité du Québec et de sa littérature est devenue un objet significatif de réflexion et une avenue interprétative dont on explicite de plus en plus les ramifications. L'américanité de la littérature québécoise a donné lieu à un premier bilan en 1990 (Melançon, 1990b in Morency: 245) dans la foulée de numéros thématiques de revues. La problématique a ses auteurs consacrés (J. Godbout, J. Poulin), ses thèmes privilégiés (l'espace, le temps, la Californie, le voyage) et même ses premières formes de résistance (Ricard, 1988, in Morency: 248).

L'étude de Jean Morency risque de relancer une problématique qui pouvait donner l'impression d'un certain piétinement. L'auteur appartient à une génération de jeunes chercheurs dont certains satisfont enfin à des attentes formulées par Benoit Melançon: ils lisent les auteurs américains et la critique américaine et se mettent en position intellectuelle de faire la comparaison. Car l'américanité ce n'est pas que du Kérouac généralisé, du On the Road; c'est aussi l'identification de similitudes et de dissimilitudes entre les littératures des Amériques (Morency, 1991a, in Morency:146), c'est, fondamentalement, sortir du cercle infernal 
162

de La France et nous, du rapport métropole-colonie et penser que les littératures coloniales ou ex-coloniales doivent être tout autant comparées entre elles qu'aux métropoles (Londres, Paris, Madrid, Lisbonne) qui leur ont donné naissance.

Jean Morency poursuit une analyse du mythique, du mythe, ce "récit" d'une histoire fondamentale qui fonde et fournit des modèles, cette représentation "d'un événement primordial" qui traverse une culture ou une littérature naissantes. L'ouvrage dégage un imaginaire commun aux sociétés américaines confrontées à "un conflit fondateur" et à une dualité culturelle fondamentale: leur appartenance "à la fois à la sphère européenne et à celle du Nouveau Monde en voie de s'inventer". Cette dualité, présente de multiples façons dans les personnages des littératures étatsunienne et québécoise - Rip van Winkle de Washington Irving, Nathy Bumppo de James Fenimore Cooper, Hester Prynne de Nathaniel Hawthorne, le capitaine Achab d'Herman Melville ou Samuel Chapdelaine et François Paradis de Louis Hémon, Menaud de Félix-Antoine Savard, le Survenant ou Didace Beauchemin de Germaine Guévremont - oppose constamment la stabilité à l'aventure, la sédentarisation au nomadisme, la civilisation à la sauvagerie, la montagne au Nord, "l'attachement" à "l'arrachement". Cette analyse du mythe américain se poursuit dans les œuvres de Gabrielle Roy, d'André Langevin, de JeanYves Souci, de Robert Lalonde, de Julien Bigras et de Jacques Poulin. C'est dire l'importance d'une trajectoire qui traverse le siècle et contribue à fonder la pertinence et la valeur de l'analyse.

L'auteur conclut à l'existence non seulement de "confluences de l'imaginaire" mais surtout d'une "splendide autonomie de l'imaginaire continentale" qui serait cette "histoire idéelle d'une métamorphose de l'homme au contact du continent américain".

Cette étude fera aussi époque par sa méthode: la mythanalyse. Voilà une méthode qui exige de la culture et qui contrastera avec les méthodes usuelles de la sémiotique ou de la sociocritique. Les familiers de la psychanalyse seront moins étonnés face à cette approche mais les analystes habitués à l'histoire ou à la sociologie de la littérature s'interrogeront sur les dimensions "psychologisantes" de la mythanalyse. Il y a dans cette approche moins une atemporalité que de longues temporalités peut-être plus susceptibles de révéler des structures, des archétypes de cultures qui cherchent et découvrent une cohérence inédite. 
Celles et ceux qu'intéresse le renouvellement des problématiques trouveront dans cet ouvrage matière à lecture et à plaisir.

Yvan Lamonde 